\title{
Editorial \\ Advanced Control and Estimation Concepts and New Hardware Topologies for Future Mobility
}

\author{
Francis F. Assadian
}

Citation: Assadian, F.F. Advanced Control and Estimation Concepts and New Hardware Topologies for Future Mobility. Energies 2022, 15, 1568. https://doi.org/10.3390/ en15041568

Received: 2 February 2022 Accepted: 2 February 2022 Published: 21 February 2022

Publisher's Note: MDPI stays neutral with regard to jurisdictional claims in published maps and institutional affiliations.

Copyright: (C) 2022 by the author. Licensee MDPI, Basel, Switzerland This article is an open access article distributed under the terms and conditions of the Creative Commons Attribution (CC BY) license (https:// creativecommons.org/licenses/by/ $4.0 /)$.
Department of Mechanical and Aerospace Engineering, University of California Davis, Davis, CA 95616, USA; fassadian@ucdavis.edu

Current transportation and, in general, mobility have a negative impact on our environment. It is well known that our transportation makes up a large portion of the GHG emissions around the world. In California alone, transportation is the largest energyconsuming and greenhouse-gas-emitting sector, making up slightly over $40 \%$ of the state's GHG emissions.

The three technology pillars for tackling this issue with cost-effective solutions are (a) Electrification, (b) Advanced Control and Optimization, and (c) Virtual sensing. This Special Issue presents the latest research and work of various world-renowned academic institutions, through 10 papers, on the impact of these aforementioned pillars on Future Mobility.

Wang et al. [1] investigated the impact of differential drive assist steering (DDAS) on the steering assistance and the driver steering effort. In this paper, the authors proposed a unique control strategy to account for the tire nonlinear characteristics and hence, results in improved tracking accuracy and subjective steering feel.

Topić et al. [2] developed a simulation tool to support decision-making processes for planning city bus transport electrification. The simulation tool is designed to use real driving cycles and techno-economic data to compute the optimal powertrain type, number of e-buses and required charging stations, and predict the total cost of ownership, including investment and return on investment cost/benefit analysis.

Nazari et al. [3] focused their research work on an innovative low-voltage hybrid device that enables engine boosting and downsizing in addition to mild hybrid functionalities. The proposed configuration uses a planetary gear set and a brake to permit the power split supercharger (PSS) to share a $9 \mathrm{~kW}$ motor between supercharging the engine and direct torque supply to the crankshaft. Utilizing an adaptive equivalent consumption minimization energy management strategy, the proposed combined system shows a fuel consumption reduction of $18.4 \%$ over the standard FTP75 cycle.

Jang et al. [4] designed an algorithm for a shuttle bus with four in-wheel electric motors to optimize the front and rear axle tractions. In addition to optimizing traction, they have considered the input terminal voltage changes during the driving cycle. They showed that the proposed algorithm could improve the energy consumption by $6 \%$, using 'Manhattan Bus Driving Cycle', when compared to the conventional vehicle.

Zhang et al. [5] investigated optimal power management of a fuel cell hybrid small UAV for the maximization of flight time in an uncertain (stochastic) environment. The power management accounts for the limits on the rate of change of fuel cell power output while maximizing the flight time duration. The simulation results indicate the capability of up to $2.7 \mathrm{~h}$ of flight time.

Filipozzi et al. [6] formulated the estimation of tire normal force as an input estimation. Then, two observers are proposed to solve this problem by using a standard quarter-car suspension model. The first observer is based on a newly developed concept called YCOO (Youla Controller Output Observer). The second observer is the Kalman filter approach 
utilizing an Unbiased Minimum Variance filter. A detailed comparative analysis between these two approaches is presented in this work.

Anselma [7] utilized a multi-objective offline optimal control approach as a speed target generator for the following vehicle adaptive cruise control (ACC). This offline approach is based on dynamic programming. The intent of this offline optimal control approach is to minimize energy consumption while enhancing passenger comfort. The approach is flexible enough to be implemented in a wide range of powertrain configurations from conventional to power-split HEV.

$\mathrm{Li}$ et al. [8] studied road traffic flow models, and speed prediction methods for New Energy Vehicle are provided. Furthermore, the influence of vehicle lateral dynamics, including correlation control methods, for vehicle speed prediction is reviewed. The authors provide a potential application of the aforementioned concepts for the next generation of intelligent transportation systems.

Arasteh et al. [9] investigated a comparative analysis of three different smart brakeby-wire actuators. These three actuators consisted of Electro-Hydraulic Brakes, ElectroMechanical Brakes, and Electronic Wedge Brakes. The authors proposed an objective metric based on energy usage, maximum power requirement, and dynamic responsiveness. They modeled the plants using an energetic modeling method and designed robust controllers utilizing Youla parameterization technique. The authors then performed both linear and nonlinear optimization on the controlled plants and compared the actuator performances based on the specified objective function.

Mallon et al. [10] explored the modeling and control of a lithium-ion battery and ultracapacitor hybrid energy storage system for an electric vehicle for improved battery lifespan and energy consumption. They developed an optimal aging-aware energy management strategy that controls both battery and ultra-capacitor aging and compared these results to strategies that control only battery aging, strategies with no aging, and non-optimal strategies. A case study on an electric bus showed a $28.2 \%$ improvement in battery lifespan while requiring only a $7.0 \%$ decrease in fuel economy.

The contributions from the research works included in this Special Issue offer new data, information, and findings to continue the R\&D effort in the field of Future Mobility, with the aim of stimulating the research community to further contribute to the development of the field.

I wish to thank the authors for their contributions to this Special Issue.

Funding: This research received no external funding.

Conflicts of Interest: The author declares no conflict of interest.

\section{References}

1. Wang, J.; Wang, X.; Luo, Z.; Schuler, J.; Assadian, F. Active Disturbance Rejection Control of Differential Drive Assist Steering for Electric. Energies 2020, 13, 2647. [CrossRef]

2. Topić, J.; Soldo, J.; Maletić, F.; Skugor, B.; Deur, J. Virtual Simulation of Electric Bus Fleets for City Bus Transport Electrification Planning. Energies 2020, 13, 3410. [CrossRef]

3. Nazari, S.; Siegel, J.; Middleton, R.; Stefanopoulou, A. Power Split Supercharging: A Mild Hybrid Approach to Boost Fuel Economy. Energies 2020, 13, 6580. [CrossRef]

4. Jang, I.-G.; Li, C.-S.; Hwang, S.-H. Energy Optimization of Electric Vehicles by Distributing Driving Power Considering System State Changes. Energies 2021, 14, 594. [CrossRef]

5. Zhang, J.; Kolmanovsky, I.; Amini, M.R. Stochastic Drift Counteraction Optimal Control of a Fuel Cell-Powered Small Unmanned Aerial Vehicle. Energies 2021, 14, 1304. [CrossRef]

6. Filipozzi, L.; Assadian, F.; Kuang, M.; Johri, R.; Velazquez, J. Estimation of Tire Normal Forces including Suspension Dynamics. Energies 2021, 14, 2378. [CrossRef]

7. Anselma, P.G. Optimization-Driven Powertrain-Oriented Adaptive Cruise Control to Improve Energy Saving and Passenger Comfort. Energies 2021, 14, 2897. [CrossRef]

8. Li, L.; Coskun, S.; Wang, J.; Fan, Y.; Zhang, F.; Langari, R. Velocity Prediction Based on Vehicle Lateral Risk Assessment and Traffic Flow: A Brief Review and Application Examples. Energies 2021, 14, 3431. [CrossRef] 
9. Arasteh, E.; Assadian, F. A Comparative Analysis of Brake-by-Wire Actuators Using Optimization Strategies. Energies 2022, 15, 634. [CrossRef]

10. Mallon, K.; Assadian, F. A Study of Control Methodologies for the Trade-Off between Battery Aging and Energy Consumption on Electric Vehicles with Hybrid Energy Storage Systems. Energies 2022, 15, 600. [CrossRef] 